\title{
PREVALENCE OF PRIMARY DYSMENORRHEA IN YOUNG WOMEN- AN INSTITUTIONAL STUDY
}

\author{
Jayanthi Potharaju ${ }^{1}$, Prasad Usha ${ }^{2}$ \\ ${ }_{1}^{1}$ Associate Professor, Obstetrics \& Gynaecology, Siddhartha Medical College, Vijayawada, Andhra Pradesh. \\ 2Associate Professor, Obstetrics \& Gynaecology, Siddhartha Medical College, Vijayawada, Andhra Pradesh.
}

\section{ABSTRACT}

\section{BACKGROUND}

Dysmenorrhea is a common menstrual problem which is encountered in young women and needs emphasis. It leads to social withdrawal, absenteeism from school and work.

The aim of the study is to know the prevalence of primary dysmenorrhea in unmarried women less than 25 years of age without organic pathology and to understand the distribution of various risk factors.

\section{MATERIALS AND METHODS}

This is a hospital-based, prospective, cross-sectional study conducted for a period of 1 year. Unmarried women $<25$ years without any organic pathology attending the Gynaecology Outpatient Department with complaints of dysmenorrhea were included in the study. A questionnaire was given to them and results tabulated.

\section{RESULTS}

Prevalence of dysmenorrhea was 58\%, 17\% presented with severe dysmenorrhea. Social withdrawal was seen in $12 \%$ of cases. Dysmenorrhea beyond 17 years was seen in 54\% of cases, $48 \%$ were from rural areas, 58\% cases were from low socioeconomic group and $32 \%$ were underweight. $59 \%$ of cases attained menarche after 12 years of age and $41 \%$ before 12 years. Irregular menstruation was seen in 38\% of cases, positive family history was seen in $35 \%$ of cases. $92 \%$ of cases had dysmenorrhea during menstruation. $93 \%$ cases adopted more than one method as therapy, they being, application of heat, abdominal massage and intake of anti-inflammatory drugs (NSAIDS).

\section{CONCLUSION}

Dysmenorrhea in young women is a major problem and needs to be effectively managed. In the present study, $17 \%$ suffered from severe dysmenorrhea. Social withdrawal was seen in $12 \%$ of cases. The subjects who consumed egg, fruits and tea everyday suffered from mild dysmenorrhea. Majority of the subjects took Paracetamol as a treatment for dysmenorrhea. Severe dysmenorrhea was controlled by intake of oral contraceptives.

\section{KEYWORDS}

Primary Dysmenorrhea, Prevalence, Young Women, Risk Factors.

HOW TO CITE THIS ARTICLE: Potharaju J, Usha P. Prevalence of primary dysmenorrhea in young women- An institutional study. J. Evolution Med. Dent. Sci. 2017;6(95):6948-6951, DOI: 10.14260/jemds/2017/1508

\section{BACKGROUND}

Menstruation occurs when the uterus sheds its lining once a month. Some amount of pain, cramping is normal. Dysmenorrhea is known as a painful period during menstruation. There are two types of dysmenorrhea, primary and secondary. Primary dysmenorrhea occurs in women who experience pain before or during menstruation and is common in adolescents. A woman who had normal periods but later develops dysmenorrhea is known as secondary dysmenorrhea and is due to organic pathology in the uterus. Some women are at higher risk and the risk factors are age $<20$ years, family history of dysmenorrhea, smoking, heavy bleeding, irregular bleeding, menarche before 12 years, low body weight and nulliparous women.[1] Dysmenorrhea is estimated to affect $25 \%$ of women mainly in late teens.[2]

'Financial or Other Competing Interest': None.

Submission 20-10-2017, Peer Review 04-12-2017,

Acceptance 11-12-2017, Published 23-12-2017.

Corresponding Author:

Prasad Usha,

Q No. 49-3-3,

Lalithanagar,

Visakhapatnam- 530016

Andhra Pradesh.

E-mail: ushaprasad411@gmail.com

DOI: $10.14260 /$ jemds $/ 2017 / 1508$
The hormone called prostaglandins trigger muscle contraction in uterus that expels endometrium. The level increases before menstruation. In older women, organic pathology is more common cause of dysmenorrhea, like fibroids, adenomyosis or endometriosis. In married women, the cause of dysmenorrhea could be due to ectopic pregnancy, pelvic inflammatory disease and interstitial cystitis. Hence, in all the cases of dysmenorrhoea, ultrasonographic examination is a must. Majority take treatment at home by applying heating pad, regular exercises, massaging abdomen, doing yoga, antiinflammatory drugs and multivitamins. Survey in Norway showed $14 \%$ of females between ages 25 to 35 years, experience severe symptoms with dysmenorrhea which abstains them from work. ${ }^{[3]}$ In the present study, an attempt was made to analyse the prevalence and distribution of risk factors in cases of primary dysmenorrhea in unmarried young women.

\section{MATERIALS AND METHODS}

This is a hospital-based, prospective, cross-sectional study conducted for a period of 1 year from January 2016 to December 2016. Unmarried women less than 25 years of age with complaints of abdominal pain during or just before menstruation attending the Gynaecology Outpatient Department were included in the study. All the patients were subjected for ultrasonographic examination to rule out any 
organic pathology. Cases with organic pathology were excluded from the study.

100 cases were randomly selected and a questionnaire in local language/English was given to them and data was analysed and tabulated using percentages.

\section{The Questionnaire was-}

1. Name and Address.

2. Age.

3. Education.

4. Economic status: $<10,000 /$ month; $>10,000 /$ month.

5. Family history of dysmenorrhea.

6. Habitat: Rural/Urban/Tribal.

7. Family type: Nuclear/Large.

8. Dietary Eggs/Fruits/Tea/Coffee/Coke/Chocolate/Alcohol. habits:

9. Weight.

10. Age of menarche.

11. Any other chronic disorder.

12. Excessive menstruation/irregular menstruation.

13. Associated symptoms: abdominal bloating/breast tenderness/insomnia/social withdrawal/poor concentration/irritability.

14. Dysmenorrhea: before menstruation/during menstruation.

15. Leading to drop out from college/work.

16. Therapy: remedies/Allopathy/Homeopathy/Ayurvedic.

Home

Dysmenorrhea was graded based on the following criteria:

- Grade 1: Mild pain during menstruation.

- Seldom inhibits normal activity.

- Analgesics are seldom required.

- Grade 2: Moderate pain during menstruation.

- Daily activity affected.

- No absence from work.

- Analgesics required and give relief.

- Grade 3: Severe pain during menstruation.

- Activity clearly inhibited.

- Absence from work.

- Poor effect of analgesics.

- Associated with headache, fatigue, vomiting, diarrhoea.

\section{RESULTS}

The grades of dysmenorrhea; mild dysmenorrhea was seen in $61 \%$ of cases, moderate dysmenorrhea in $22 \%$ of cases and $17 \%$ presented with severe dysmenorrhea. [Table 1].

\begin{tabular}{|c|c|c|}
\hline Grades of Dysmenorrhea & Number of Cases & Percentage \\
\hline Grade 1(mild) & 61 & 61 \\
\hline Grade 2 (moderate) & 22 & 22 \\
\hline Grade 3 (severe) & 17 & 17 \\
\hline Total & 100 & 100 \\
\hline
\end{tabular}

The symptoms associated with dysmenorrhea was nausea and vomiting (78\%), poor concentration (32\%), irritability (21\%), breast tenderness (20\%), insomnia (15\%) and social withdrawal in $12 \%$ of cases [Table 2].

\begin{tabular}{|c|c|c|}
\hline $\begin{array}{l}\text { Associated } \\
\text { symptoms }\end{array}$ & Number of cases & Percentage \\
\hline $\begin{array}{l}\text { Nausea and } \\
\text { Vomiting }\end{array}$ & 78 & 78 \\
\hline Insomnia & 15 & 15 \\
\hline Poor concentration & 32 & 32 \\
\hline Breast tenderness & 20 & 20 \\
\hline Social withdrawal & 12 & 12 \\
\hline Irritability & 21 & 21 \\
\hline Total & 100 & 100 \\
\hline
\end{tabular}

The dietary history in subjects with dysmenorrhea was: consumption of $1 \mathrm{egg} /$ day (78\%), fruits 1/day (55\%), tea 4 cups/day (68\%), coffee 3 cups/day (79\%), coke $200 \mathrm{~mL} /$ day (15\%), chocolate 2 bars/day (32\%) and alcohol consumption occasionally in $3 \%$ of cases. [Table 3].

\begin{tabular}{|c|c|}
\hline Dietary Habits & Percentage of Cases \\
\hline Eggs: 1 /day & 78 \\
\hline Fruits :1/day & 55 \\
\hline Tea $: 4$ cups/day & 68 \\
\hline Coffee: 3 cups/day & 79 \\
\hline Coke $: 200$ mL/day & 15 \\
\hline Chocolate: 2 bars/day & 32 \\
\hline Alcohol: Occasional & 3 \\
\hline \multicolumn{2}{|c|}{ Table 3. Dietary Habits } \\
\hline
\end{tabular}

Dysmenorrhea beyond 17 years was seen in $54 \%$ of cases and $46 \%$ of cases occurred in cases less than 17 years of age. Dysmenorrhea was seen in $5 \%$ of tribal cases, $48 \%$ were from rural areas and $47 \%$ from urban area. $58 \%$ cases were from low socioeconomic group. $62 \%$ belonged to nuclear family. $32 \%$ were underweight, $20 \%$ were overweight and $48 \%$ were of normal weight. [Table 4].

\begin{tabular}{|c|c|c|}
\hline Parameters & No. of cases & \% \\
\hline Age & & \\
\hline$\leq 17$ years & 46 & 46 \\
\hline$>17$ years & 54 & 54 \\
\hline Habitat & 48 & 48 \\
\hline Rural & 47 & 47 \\
\hline Urban & 5 & 5 \\
\hline Tribal & & \\
\hline Income of family & 58 & 58 \\
\hline$<10,000 /$ month & 42 & 42 \\
\hline$>10,000 /$ month & 62 & 62 \\
\hline Family type & 38 & 38 \\
\hline Nuclear & & \\
\hline Large & 48 & 48 \\
\hline BMI & 32 & 20 \\
\hline $18-24.9 \mathrm{~kg} / \mathrm{m}^{2}$ (Normal weight) & 32 \\
\hline $25-29.9 \mathrm{~kg} / \mathrm{m}^{2}$ (Overweight) & & \\
\hline$<18 \mathrm{~kg} / \mathrm{m}^{2}$ (Underweight) & \multicolumn{2}{|c|}{} \\
\hline Table 4. Demographic Parameters in Dysmenorrhea
\end{tabular}

$59 \%$ of cases attained menarche after 12 years of age and $41 \%$ attained below 12 years. Irregular menstruation was seen in $38 \%$ of cases, excessive menstruation in $28 \%$ and normal menstruation in $34 \%$ of cases. Positive family history was seen in $35 \%$ of cases. $92 \%$ of cases had dysmenorrhea during menstruation, 39\% had taken therapy. [Table 5]. 


\begin{tabular}{|c|c|c|}
\hline Details & Number of Cases & Percentage \\
\hline Age of menarche & 41 & 41 \\
\hline$\leq 12$ years & 59 & 59 \\
\hline$>12$ years & 28 & 28 \\
\hline Excessive menstruation & 38 & 38 \\
\hline Irregular menstruation & 34 & 34 \\
\hline Normal menstruation & & \\
\hline $\begin{array}{c}\text { Family history of } \\
\text { dysmenorrhea }\end{array}$ & 35 & 35 \\
\hline Yes & 65 \\
\hline No & 65 & 8 \\
\hline Dysmenorrhea & 8 & 92 \\
\hline Before menstruation & 92 & 39 \\
\hline During menstruation & & 61 \\
\hline $\begin{array}{c}\text { Treatment taken for } \\
\text { dysmenorrhea }\end{array}$ & 39 & 61 \\
\hline \multicolumn{2}{|c|}{ Yes } & \\
\hline \multicolumn{2}{|c|}{ No } & Menstrual History \\
\hline \multicolumn{2}{|c|}{} \\
\hline
\end{tabular}

93\% cases adopted more than one method of therapy, they being application of heat, abdominal massage and intake of anti-inflammatory drugs (NSAIDs). $10 \%$ of cases did exercise or yoga. $80 \%$ of cases applied either heat or did abdominal massage with or without oil and these cases mainly suffered with grade 1 dysmenorrhea. Cases with severe dysmenorrhea who did not respond to NSAIDs were put on oral contraceptives and they responded well. [Table 6].

\begin{tabular}{|c|c|}
\hline Therapy & Percentage of Cases \\
\hline Allopathy medicine & 39 \\
\hline Ayurvedic/Homeopathy & 61 \\
\hline Apply heat & 80 \\
\hline Apply massage & 80 \\
\hline Drinking tea & 22 \\
\hline Exercises/yoga & 10 \\
\hline $\begin{array}{l}\text { Eating foods like papaya, } \\
\text { pumpkin seeds }\end{array}$ & 32 \\
\hline Combination of methods & 93 \\
\hline \multicolumn{2}{|c|}{ Table 6: Treatment Adopted in Cases of Dysmenorrhec } \\
\hline
\end{tabular}

\section{DISCUSSION}

In literature the prevalence of dysmenorrhea varied between $28 \%$ to $89.5 \%{ }^{[4,5,6,7]}$ In the study by Polat et al,[7] the prevalence of dysmenorrhea was $72.7 \%$. 66.2\% suffered from severe and moderate dysmenorrhea which was similar to the study by Burnett et al. ${ }^{[4]}$ In the study conducted on 432 nurses by Chaya Chinda $\mathrm{C}$ et al, [8] the prevalence of dysmenorrhea was $25.1 \%$. In Tang Chaik et al[9] study, the prevalence of dysmenorrhoea was $84.2 \%, 4.7 \%$ had severe dysmenorrhea. In Cakir M et al[10] study, the prevalence was $89.5 \%$ with severe dysmenorrhea being $10 \%$. Andersch B et al[11] reported dysmenorrhoea in $72 \%$ of women, $15 \%$ of cases suffered from severe dysmenorrhea. Patel V et al[12] reported moderate-tosevere dysmenorrhea in $33.37 \%$ of cases. In the study by Balbic et al,[13] primary dysmenorrhoea was seen in $85 \%$ of cases. Dawood MY[14] documented $50 \%$ of young women with dysmenorrhea. Avasarala AK et al[15] in their study found that the prevalence of dysmenorrhea was $54 \%$. Alaettin UN S et al[16] reported prevalence of dysmenorrhea as $72.7 \%$.

In the present study, prevalence of dysmenorrhea between the age group of 11 years to 22 years was $58 \%$. Severe and moderate dysmenorrhea constituted $22 \%$ and $17 \%$ respectively in the present study. This indicates that dysmenorrhea is still an important public health problem which has negative effect on social environment, work and psychological status.

In the study by Tangchaik et al,[9] common associated symptom was stomach ache $(78 \%)$ followed by backache (58.9\%), mood change (56.9\%), poor concentration (60\%) and $45.6 \%$ reported school or work absenteeism. In the study by Avasarala AK et al, ${ }^{[15]}$ sickness absenteeism varied from 28 $48 \%$, associated with nausea in $55 \%$, and vomiting in $24 \%$. In the present study, the symptoms associated with dysmenorrhea were nausea and vomiting (78\%), poor concentration $(32 \%)$, irritability $(21 \%)$, breast tenderness (20\%), insomnia (15\%) and social withdrawal (12\%).

Epidemiological studies have shown a link between dysmenorrhea and several risk factors. Some researchers have documented coffee consumption was an important risk factor for dysmenorrhea. Menstrual bleeding more than seven days was associated dysmenorrhea. Family history of dysmenorrhea had higher prevalence of dysmenorrhea which is consistent with many studies in literature.[7] Balbi C et al[13] noted that a higher consumption of fish, eggs, fruit and a lower consumption of wine is correlated with a lower frequency of dysmenorrhea. He observed that early menarche was related to increase in the prevalence and severity of dysmenorrhea. Long and heavy menstrual flow was associated with severity of pain. Chaya Chinda $\mathrm{C}$ et al[8] observed that younger age, nulligravida, lower income, coffee consumption of greater than $1 \mathrm{cup} /$ day, complained of moderate-to-severe dysmenorrhea and had negative attitude towards menstruation. Di Cintio E et al[17] analysed 106 women with moderate and severe dysmenorrhea observed that women with irregular, long, heavy menstrual flow had dysmenorrhea and there was no distribution with dietary habits. Andersch B et al[11] showed a significant correlation between dysmenorrhea. Polat et al[7] found mean age of students suffering with dysmenorrhea was $21 \pm 2.13$, mean menarche age was $13.3 \pm 1.4$, menstrual frequency was $32.58 \pm 19.8$ days.

In the study by Burnett MA et al, ${ }^{[4]}$ socioeconomic status, nulliparity, earlier age at menarche was not independently associated with primary dysmenorrhea. In the study by Tanchaik et al,[9] 98.8\% of patients with dysmenorrhea got relief with Paracetamol. Vicdan K et al[18] noted that the average menarcheal age was $13.28 \pm 1.09$ and menstrual cycles were between $20-35$ days, $8.1 \%$ had pain during menstruation, 25.6\% missed school.[18] Pullon S et al[19] analysed 1826 women and noted $50 \%$ had dysmenorrhea. Maximum cases occurred between 20-24 years. There was no distribution with body mass. Response was better with oral contraceptive pills.

In the present study, the dietary history in subjects with dysmenorrhea was: consumption of $1 \mathrm{egg} /$ day $(78 \%)$, fruits $1 /$ day ( $55 \%$ ), tea 4 cups/day (68\%), coffee 3 cups/day (79\%), coke $200 \mathrm{~mL} /$ day (15\%), chocolate 2 bars/day (32\%) and alcohol consumption occasionally in $3 \%$ of cases. The cases who consumed egg, fruits and tea had mild dysmenorrhea and cases with intake of coffee three times a day had moderate-tosevere dysmenorrhea. Dysmenorrhea beyond 17 years was seen in $54 \%$ of cases and $46 \%$ of cases occurred less than 17 years of age. Dysmenorrhea was seen in $5 \%$ of tribal cases, $48 \%$ were from rural areas and $47 \%$ from urban areas. $58 \%$ cases were from low socioeconomic group. $62 \%$ belonged to nuclear family. $32 \%$ were underweight, $20 \%$ were overweight 
and $48 \%$ were of normal weight. Severity of dysmenorrhea was not affected by weight.

$59 \%$ of cases attained menarche after reaching 12 years of age and $41 \%$ attained below 12 years. Irregular menstruation was seen in $38 \%$ of cases, excessive menstruation in $28 \%$ and normal menstruation in $34 \%$ of cases. Positive family history was seen in $35 \%$ of cases. $92 \%$ of cases had dysmenorrhea during menstruation, $39 \%$ had taken therapy.

93\% cases adopted more than one method of therapy, they being, application of heat, abdominal massage and intake of anti-inflammatory drugs (NSAIDS). $10 \%$ of cases did exercise or yoga. $80 \%$ of cases applied either heat or did abdominal massage with or without oil and these cases mainly suffered with grade 1 dysmenorrhea. Cases with severe dysmenorrhea who did not respond to NSAIDS were put on oral contraceptives with good response.

\section{CONCLUSION}

Dysmenorrhea in young women is a major problem and needs to be effectively managed. In the present study, prevalence of dysmenorrhea was $58 \%$ and $17 \%$ suffered from severe dysmenorrhea. Social withdrawal was seen in $12 \%$ of cases. $58 \%$ were from low socioeconomic group, 32\% were underweight and 59\% attained menarche after 12 years of age. Family history of dysmenorrhea was seen in 35\% of the cases. The subjects who consumed egg, fruits and tea everyday had mild dysmenorrhea and cases with intake of coffee three times a day had moderate-to-severe dysmenorrhea. Majority of cases applied heat, abdominal massage with oil and took Paracetamol as a treatment for dysmenorrhea. Severe dysmenorrhea was controlled by intake of oral contraceptives.

\section{REFERENCES}

[1] Osayande AS, Mehulic S. Diagnosis and initial management of dysmenorrhea. American family Physician 2014;89(5):341-6.

[2] Janssen EB, Rijker AC, Hoppenbrouwers K, et al. Prevalence of endometriosis diagnosed by laparoscopy in adolescents with dysmenorrhea or chronic pelvic pain: a systemic review. Human Reproduction Update 2013;19(5):570-82.

[3] French L. Dysmenorrhea in adolescents: diagnosis and treatment. Peadiatr Drugs 2008;10(1):1-7.

[4] Burnett MA, Antao V, Black A, et al. Prevalence of primary dysmenorrhea in Canada. J Obstet Gynaecol Can 2005;27(8):765-70.

[5] Pitts MK, Ferns JA, Smith AM, et al. Prevalence and correlates of three types of pelvic pain in a nationally representative sample of Australian women. Med J Aust 2008;189(3):138-43.
[6] Nur N, Sumer H. Prevalence of dysmenorrhea and related risk factors in adolescents. Surekli Tip Egihmi Dergisi 2008;7:27-30.

[7] Polat A, Celik H, Gurates B, et al. Prevalence of primary dysmenorrhea in young adult female University students. Arch Gynecol Obstet 2009;279(4):527-32.

[8] Chayachinda C, Rattanachaiyanont M Phattharayuttawat $\mathrm{S}$, et al. Premenstrual syndrome in Thai Nurses. J Psychosom Obstet Gynaecol 2008;29(3):199-205.

[9] Tangchai K, Titapant V, Boriboonhirunsarn D. Dysmenorrhea in Thai adolescents: prevalence, impact and knowledge of treatment. J Med Assoc Thai 2004;87(Suppl 3):S69-73.

[10] Cakir M, Mungan I, Karakas T, et al. Menstrual pattern and common menstrual disorder among University students in Turkey. Pediatr Int 2007;49(6):938-42.

[11] Andersch B, Milsom I. An epidemiologic study of young women with dysmenorrhea. Am J Obstet Gynecol 1982;144(6):655-60.

[12] Patel V, Tanksale V, Sahasrabhojanee M, et al. The burden and determinants of dysmenorrhea: a population-based survey of 2262 Women in Goa, India. BJOG 2006;113(4):453-63.

[13] Balbi C, Musone R, Menditto A, et al. Influence of menstrual factors and dietary habits on menstrual pain in adolescence age. Eur J Obstet Gynecol Reprod Biol 2000;91(2):143-8.

[14] Dawood MY. Dysmenorrhea. Clin Obstet Gynecol 1990;33(1):168-78.

[15] Avasarala AK, Panchangam S. Dysmenorrhea in different settings: are the rural and urban adolescent girls perceiving and managing the dysmenorrhea problem differently? Indian J Community Med 2008;33(4):246-9.

[16] Unsal A, Ayranci U, Tozan M, et al. Prevalence of dysmenorrhea and its effect on quality of life among a group of female University students. Ups J Med Sci 2010;115(2):138-45.

[17] Di Cintio E, Parazzini F, Tozzi L, et al. Dietary habits, reproductive and menstrual factors and risk of dysmenorrhea. Eur J Epidemiol 1977;13(8):925-30.

[18] Vicdan K, Kukner S, Dabakoglu T, et al. Demographic and Epidemiological features of female adolescents in Turkey. J Adolesc Health 1996;18(1):54-8.

[19] Pullon S, Reinken J, Sparrow M. Prevalence of dysmenorrhea in Wellington women. N Z Med J 1988;101(839):52-4. 